patient's record envelope. Otherwise, GPs would edit reports by the judicious use of scissors and the wastepaper basket!

There then followed a general discussion in which the following topics were raised:

the place of community mental health centres (in the UK, as opposed to the perjorative experience of this terminology in the USA);

the place of other agencies in primary health care consultation, for example social workers, voluntary agencies and housing departments;

the most effective use of resources, with doubts whether the needs of the chronically ill and the severely acutely ill were best served by such liaisons;

the problem of relating to the single-handed GPs possibly by seeing patients from a number of individual GPs in one central location;

the need to evaluate existing schemes, and to determine the different profiles of patients seen in GP settings, in psychiatric outpatient departments, and in community mental health centres a reminder that while GPs see most of the less mentally disordered, psychiatrists in turn see most of the very disturbed; the independent practitioner status claimed by nurse therapists who want to work directly with GPs who in turn may not welcome this

Dr John Horder in his closing remarks asked three questions:

(i) Will this style of working spread, and if so what new forms might it take?

(ii) Who will evaluate existing schemes, before there is an explosive 'take-of' in new directions?

(iii) Do psychiatrists appreciate how much they can be valued both as teachers and as supporters when working in GP settings?

RosS MITCHELL Convenor of the Sub Group of Psychiatrists working in GP Settings of the Section of Social and Community Psychiatry

\title{
Mental Handicap Nurses-Training in Psychiatric Aspects of Care Section for the Psychiatry of Mental Handicap
}

Changing patterns of care for the mentally handicapped are having a profound effect on the roles of all professions concerned-not the least mental handicap nurses. Many will continue their caring role in the community. Others will work as community mental handicap nurses providing domiciliary support to families and local authority services. Those remaining in the hospital service will be increasingly concerned with the care of the psychiatrically ill and behaviourally disturbed, the profoundly and multiply handicapped and the elderly. This has important implications for training nursing staff both at present and in the future.

In the long term the NHS will have a continuing responsibility to provide a service for mentally handicapped people who develop psychiatric illnesses or exhibit severe behavioural problems and certain mentally handicapped offenders. Recent epidemiological studies indicate that between $40 \%$ and $50 \%$ of mentally handicapped adults and children suffer superadded psychiatric disorder. A specialised service is required because of the unique features attending the occurrence, nature, diagnosis and treatment of psychiatric disorder in mentally handicapped people, organised and staffed by appropriately trained and experienced doctors, nurses and other staff who have a wide knowledge of the general field of mental handicap. Specialised psychiatric units for the mentally handicapped are increasingly being developed within mental handicap services throughout the country.

Nurses working in these services should have a primary training in mental handicap with experience and possibly accreditation in psychiatric nursing. Nurses with a primary qualification in psychiatry and additional training in mental handicap would also be acceptable.

The Section is concerned that these changes in mental handicap nursing practice are not adequately reflected in current nurse training syllabuses at both basic and postbasic levels. Indeed the amount of time devoted to the medical and psychiatric aspects of care of the mentally handicapped has been increasingly eroded over recent years with the result that nurses are inadequately equipped to care for the profoundly and multiply handicapped and those with psychiatric disorder who are forming an increasing proportion of hospital patients.

We recommend:

(1) That the current basic training syllabus should include, preferably in the third year, a module of training in psychiatric aspects of care which should include practical experience within a specialist psychiatric unit for the mentally handicapped.

(2) The establishment of in-service training courses, including practical experience, in psychiatric aspects of the 
care of the mentally handicapped in all mental handicap hospitals and units.

(3) That nurses already working in this area or intending to do so, should be encouraged and enabled to gain further experience or the RMN qualification through secondment to psychiatric hospitals and established courses.

(4) That the ENB promote post-basic training courses in psychiatric aspects of the care of the mentally handicapped.
In the long term we consider that there needs to be a major review of nurse training in mental handicap which takes account of the different roles which will be played by mental handicap nurses as new patterns of care evolve and the possibility that different courses will be required for nurses wishing to pursue careers in different aspects of the service.

\section{Dr Anatoly Koryagin}

Dr Anatoly Koryagin, the Russian psychiatrist distinguished for his struggles against the political abuse of psychiatry in the USSR is, following his release, at present domiciled in Switzerland. He has agreed to speak to the title "The involvement of Soviet Psychiatry in the persecution of dissenters" at the College's Autumn Quarterly Meeting at Kensington Town Hall, on Thursday, 29 October 1987 at 11.45 a.m. He will, on that occasion, be presented with his certificate of Fellowship of this College.

\section{Obituary}

Editor: Henry R. Rollin

Fernando Arroyave-Portella, Consultant Psychiatrist, Alcoholic Unit, Warneford Hospital, Oxford.

Fernando Arroyave died aged 53 years on 11 April 1987. He did so in the same way he had lived: with flair and a sense of the dramatic. The first Fellow of the Royal College of Psychiatrists to have a heart transplant (at Harefields Hospital) he whispered, as he was being wheeled into theatre: "I am not going without putting up a good fight". And fight he did; alas this last battle he was unable to win. And he should have, because he was a generous, warm, thoroughly professional and fiercely independent man. He never ceased to be a Colombian. Gone with him are his bonhomie, the impish quality of his laughter and the teasing and forthright delivery of his usually well-timed profanities.

From a medical family, Columbian in origin and trained in medicine at Salamanca University, Fernando Arroyave was one of that selected band of young Spanish-speaking doctors who came to work under Felix Letemendia, that Mecenas of psychiatry, in the memorable Littlemore Hospital of the early and middle 1960 s, where it was not uncommon to see Gilbert Ryle, Carolus Oldfield, Richtie Russell, or May Davison quietly walking towards the Old Library to deliver a lecture to the trainees.

With a solid background in biological psychiatry and in electro-encephalography Fernando Arroyave came to choose, as his metier, one of the toughest of psychiatric disorders: alcoholism. Aware of the psychodynamic dimensions of the problem he decided to train as a psychoanalyst. He threw himself into his new field with his usual panache and determination, and after hundreds of training hours and thousands of miles down the M40 he emerged, at the other end, still Latinoamerican and still mercurial, perhaps greyer at the temples, but fully trained in both Jungian and group psychoanalysis.

His research into alcoholism was practical and full of common sense. He demonstrated, for example, that shorter admissions for assessment and drying out were as successful as longer ones. In the euphemistic world of the 1970s, when alcoholic units became 'Drink Problem Clinics' and 'Controlled Drinking' the new fashion, his sense of clinical balance and realism prevailed, and he wrote vigorously in favour of total abstinence.

He did not think much of those colleagues who made it easy for themselves by accepting for treatment only the few 'clients' that complied with overselective criteria. He believed that alcoholic units must offer the full range of services including acute medical and psychiatric care. Using this flexible admission policy he managed to collect one of the largest cohorts of alcoholic patients in the country. He was actively analysing this rich source of clinical information when he was finally smitten by disease. He was fond of saying that he who forgets his general psychiatry is no longer of any use even to alcoholism. 